DOI: $10.17805 /$ zpu.2018.1.17

\title{
Предчувствие антропологической катастрофы в «Записках сумасшедшего» Н. В. Гоголя
}

\author{
В. Н. МАТОНИН, Н. Н. БЕДИНА, Е. Н. ЕГОРОВА
}

СЕВЕРНЫЙ (АРКТИЧЕСКИЙ) ФЕДЕРАЛЬНЫЙ УНИВЕРСИТЕТ ИМЕНИ М. В. ЛОМОНОСОВА

Повесть русского писателя Н. В. Гоголя «Записки сумасшедшего» (1834) - одно из наиболее известных философских сочинений автора. Произведение Н. В. Гоголя осмысливается в контексте диалоговой концепции культуры М. М. Бахтина, которая предполагает возможность «превосхождения» текстом своего автора, а также возможность гениальных авторских прозрений.

В образе героя повести Аксентия Ивановича Поприщина находит отражение предчувствие «антропологической катастрофы» (М. Мамардашвили). Ее признаки Гоголь удивительно точно воплотил в художественном образе гораздо раньше, чем она была осмыслена с помощью категориального аппарата философии. Чем дальше читатель погружается в сознание героя, тем очевиднее для него становится онтологическое одиночество человека, воплощенное в безумии "брошенного в мир» (М. Хайдеггер) героя. В поисках выхода за пределы ограниченности, конечности человека Гоголь идет тем же путем, который 
обозначит Э. Кассирер, оппонирующий М. Хайдеггеру, - в осмысленное бытие культурных форм. Предчувствуя опасность антропологической катастрофы, Гоголь через своего героя предлагает человеку найти основания для собственного существования в жертвенном служении и в молитве (вере). В мире иллюзий (в “безумии от недумания») жертва, страдание - путь возвращения к реальности, невозможный без чувства Родины. В этом смысле актуальным оказывается вопрос о национальном характере прозы Гоголя.

В языке и образном строе произведения писатель находит способ показать универсальное в национальном, так как подлинный патриотизм предполагает интуитивное стремление к универсализму, к преодолению национальной замкнутости и ограниченности.

Ключевые слова: Н. В. Гоголь; русская литература; «Записки сумасшедшего»; антропологическая катастрофа; онтологическое одиночество; осмысленное бытие

\section{ВВЕАЕНИЕ}

$\Pi$ овесть русского писателя Н. В. Гоголя «Записки сумасшедшего» (1834) — одно из наиболее известных философских сочинений автора. О «бездне поэзии» и «бездне философии» в повестях Гоголя писал еще В. Г. Белинский (Белинский, 1952: 342). Рисуя сатирическую картину чиновничьего Петербурга, России и в целом Европы, Гоголь в гротесковой художественной форме, в образе мелкого чиновника - титулярного советника Поприщина, страдающего манией величия в результате неизбывного социально-психологического унижения, говорит об универсальном онтологическом одиночестве человека в мире. «Тьфу, к черту!.. Экая дрянь!. > ..> Мне подавайте человека! Я хочу видеть человека; я требую пищи той, которая бы питала и услаждала мою душу; а вместо того эдакие пустяки...» (Гоголь, 1984: 174) - негодует герой в перевернутом мире, где человек носит имя «Зверков», а собаки говорят и пишут человеческим языком.

Общей чертой исследовательских работ, посвященных «Запискам сумасшедшего», можно назвать внимание к деталям и фразам, которые позволяют сопоставить этот текст с интерпретационными возможностями произведений иных авторов. Текст Н. В. Гоголя становится особым полем сотворчества, где можно отыскать самые разные смыслы: «человек разучился думать» и «человека жалко», «в поисках себя забыл человек о душе и о Аругом», «форма для него выше содержания». Но на дне бездны есть еще надежда на спасение, хотя бездна многомерна, как картины Пабло Пикассо.

В контексте диалоговой концепции культуры М. М. Бахтина, предполагающей возможность «превосхождения» текстом своего автора, а также возможность гениальных авторских прозрений, мы обратились к произведению Н. В. Гоголя, учитывая интеллектуальный опыт философии и культурологии XX - начала XXI в. В образе героя Н. В. Гоголя мы видим предчувствие антропологической катастрофы, признаки которой автор удивительно точно воплотил в художественном образе гораздо раньше, чем она была осмыслена с помощью категориального аппарата философии.

\section{БЕЗУМИЕ ОТ НЕАУМАНИЯ}

Под антропологической катастрофой мы, вслед за А. Швейцером, М. К. Мамардашвили, А. М. Пятигорским и другими исследователями, понимаем «неспособность к собственному мышлению и все вытекающие из этой неспособности следствия» (Шарипов: Электронный ресурс; Мамардашвили, 1992: 107-121) - иначе говоря - «безумие от недумания» (Балаян, 2004: Электронный ресурс; Пятигор- 
ский, 2016). Намеренно ли в этом случае глагол «думать» выступает одним из ключевых (наряду с «понимать») в тексте произведения?

Гоголевский персонаж парадоксальным образом похож на современного человека, проблема которого заключается в несовпадении намерения и результата, в потере власти над фактами, а вместе с тем - над реальностью. С утратой патриархального жизненного уклада отношения личности с миром становятся все более опосредованными и все менее прогнозируемыми. Иллюзорность проникает в политику, экономику, отношения между людьми.

М. К. Мамардашвили в докладе «Сознание и цивилизация» утверждает: «...”антропологическая катастрофа" - это нарушение принципа первого “К” (Картезия), $<$...> которое можно выразить короткой формулой “я есть”. <..> все, что должно было быть сделано со стороны мира, уже сделано, дело теперь за тобой. И никакие противо-необходимости природы, стихийно-естественные понуждения и обстоятельства не в силах лишить человека его принципиального “я могу". Только он сам может добровольно отказаться от этой экзистенциальной привилегии, то есть стать рабом (своих привычек, общественного мнения, политического строя и т. А.)» (цит. по: Шарипов: Электронный ресурс). В начальных дневниковых записях героя Н. В. Гоголя мы в каждом смысловом нюансе можем найти черты әтого лакейства - зависимости от своих привычек, мнения окружающих, жажды власти и пр. Вот почему очевидны акценты на смыслах, объективирующих внешнее, зависть, приспособление. Сознательное и бессознательное героя содержится в осколках отражения других персонажей (переписка собачек - записи его мыслей, лакеи его подобострастие и пр.).

Н. В. Гоголь создает для своего персонажа антигуманное пространство, где $A \not д$ 2ие, вглядывание в которых должно бы стать «утверждением бытия» героя, в диалоге с которыми герой должен бы «становится тем, что он есть» (Бахтин, 1979: 294), оказываются фальшивыми зеркалами, в которых не увидеть своего истинного отражения. Невозможность обрести себя ввергает героя в безумие.

Аневниковые записи как жанровая форма произведения помогают отразить «вспышки» и «перемещения» бессознательного и сознательного: число - мартобря (между весной и осенью), 86 - между ними - 7, между днем и ночью - вечером (по-видимому, маркер переходного внутреннего состояния). Обозначения дневниковых записей подвергаются смысловому крещендо: чем мощнее уход от реальности, тем абсурднее и «клочкообразнее» ${ }^{1}$ заглавия. Аксентий ${ }^{2}$ Иванович Поприщин ищет свое место (ср. «поприще» согласно ономастилистической ноте анализа), и именно несоответствие его представлений о себе самом с реальностью усугубляет безумие.

Н. В. Гоголь наделяет «сумасшедшего» способностью понимать язык животных. Можно предположить, что здесь присутствует намек на пограничное состояние сознания Поприщина. Однако служит ли это лишь одним из доказательств его сумасшествия? А что если это не безумие, а «зазеркалье» и «складки разных измерений»? Подобно измерениям в текстах $\Lambda$. Кэрролла, О. Уайльда, Х. Борхеса и др. «Вон небо клубится передо мною; звездочка сверкает вдали; лес несется с темными деревьями и месяцем; сизый туман стелется под ногами; струна звенит в тумане; с одной стороны море, с другой Италия; вон и русские избы виднеют» (Гоголь, 1984: 184). По-видимому, читательская интерпретация не ис- 
ключает и предположения о том, что Н. В. Гоголь предсказал физические теории многомерности пространства (одно из которых - воображение Поприщина, см. запись от третьего декабря)? Или - словами Н. В. Гоголя - «физики пишут глупости»?

\section{ОБРЕТЕНИЕ ПОААИННОГО БЫТИЯ}

Сумасшествие героя заставляет его разум работать чрезвычайно напряженно. Используя предложенную Эрихом Фроммом оппозицию «разум - рассудок», мы можем говорить об утрате героем рассудка, но не разума: «Разум - это способность человека мысленно постигать мир, в противоположность рассудку, представляющему собой способность манипулировать миром вещей при помощи мышления. Разум - инструмент человека для достижения истины, рассудок - инструмент для более успешного обращения с миром; первый - человечен по своей сути, второй принадлежит к животному в человеке» (Фромм, 1995: 325). На языке Г. С. Померанца, понятия Э.Фромма соответствуют интуииии и рассудку. Он подчеркивает: «Интуиция была раньше доказательств. Мир интуиции основан на умении созерцать. Это касается не только религии, это касается всей культуры» (Померанц: Электронный ресурс). Поэтому только духовная сущность, словно самовосстанавливающийся и самоочищающийся океан, чувствуя опасность последствий антропологической катастрофы, стремится создать укрытие. Н. В. Гоголь призывает человека к этому укрытию в служении и в молитве (вере).

Вступая в диалог с героем произведения, читатель невольно занимает место самого Аксентия Ивановича - «второго» сознательного «я», которому оказывается свойственно сострадание и ирония. Чем дальше мы погружаемся в сознание героя, тем очевиднее становится онтологическое одиночество человека (одно из самых трагических его воплощений - финал повести). Заблудившийся в «зазеркалье»герой, утративший, но ищущий, даже требующий возможности сказать «я есть», позволяет, на наш взгляд, выстроить интерпретационные нити соотнесения «Записок сумасшедшего» с трудом М. Хайдеггера «Бытие и время», в котором обосновано понятие Dasein («бытие-в-себе», «тут-бытие») и такие специфические категории, как «брошенность в мир» и «ужас» (Хайдеггер, 2011).

В поисках выхода за пределы описанной Хайдеггером ограниченности, конечности человека, Гоголь идет, на наш взгляд, тем же путем, который обозначит оппонент Хайдеггера философ Э. Кассирер, - в осмысленное бытие культурных форм (Мартин Хайдеггер ..., 2001: 129-140). Герой обретает самого себя, поверив в нужность и осмысленность своего существования: «Сегодняшний день - есть день величайшего торжества! В Испании есть король. Он отыскался. Этот король я!» (Гоголь, 1984: 177).

Аксентий Поприщин «отделяется от действительности собак и департамента и воспаряет в высшей реальности - реальности нового бытия, которое, как ни комично со стороны, есть подлинное его бытие» (Золотусский, 1979: 167). Через безумие Гоголь ведет своего героя к «подлинному бытию»как бытию жертвенному. Жертва - осмысленное страдание: «...канцлер ударил меня два раза палкою по спине так больно, что я чуть было не вскрикнул, но удержался, вспомнивши, что это рыцарский обычай при вступлении в высокое звание, потому что в Испании еще и доныне ведутся рыцарские обычаи» (Гоголь, 1984: 181). 
Трагедия человека, вдруг поверившего в осмысленность собственного существования и обманувшегося, изображена Гоголем с пронзительной силой: «Нет, я больше не имею сил терпеть. Боже! Что они делают со мною! Они льют мне на голову холодную воду! Они не внемлют, не видят, не слушают меня» (там же: 183). Пройдя через страдание от физической боли и утраты смысла, герой в финале, как представляется, обретает «свободу от всякого страха действительного мира» (Мартин Хайдеггер ..., 2001: 136), буквально поднимаясь над миром: «Садись, мой ямщик, звени, мой колокольчик, взвейтеся, кони, и несите меня с этого света! Аалее, далее, чтобы не видно было ничего, ничего»), 一 и в то же время, возвращаясь к нему: «Аом ли мой синеет вдали? Мать ди моя сидит перед окном? Матушка, спаси твоего бедного сына! Урони слезинку на его больную головушку!» (Гоголь, 1984: 184).

\section{УНИВЕРСААЬНОЕ В НАЦИОНАИЬНОМ}

В мире иллюзий (в «зазеркалье») страдание - путь возвращения к реальности, невозможный без чувства Родины, но к реальности «зримой духовными очами» в «область чистой формы» (Э. Кассирер). В этом смысле актуальным оказывается вопрос о национальном характере прозы Гоголя. Будет ли «русский» автор (в узко национальном понимании этого слова) писать буквально следующее: «На улицах не было никого: одни только бабы, накрывшись полами платья, да русские купцы под зонтиками, да курьеры попадались мне на глаза» (там же: 165). Будет ли русский писатель указывать на национальную принадлежность купцов в Санкт-Петербурге?

Между тем проза Н. В. Гоголя - одно из самых ярких воплощений национального, «коренного» русского мира, в ней в полной мере явлена стихия национального языка. В центре русской грамматики находится не имя, выражающее устойчивое понятие, а глагол, актуализирующий действие и в предикате выражающий то новое, что несет в себе мысль. В тексте Гоголя идея потребности человека обрести смысл актуализируется в ключевых глаголах текста - «думать» и «понимать». «Мысль направлена словом», «слово с самого своего рождения есть для говорящего средство понимать себя» - эти слова А. Потебни имеют особое значение при анализе гоголевского текста (Потебня, 1999: 125, 162-166; Колесов, 2015: 8). В языке и мысли находит Н. В. Гоголь способ показать универсальное - в национальном. «В полете на воссоединение с целым, в музыке мирового оркестра, в звоне струн и бубенцов, в свисте ветра, в визге скрипок - родилось дитя Гоголя. Этого ребенка назвал он Россией», - пишет в 1909 г. А. Блок (Блок, 1982: 296). В определении себя русским и одновременно в отстранении от российской действительности, во взгляде извне проявляется «всечеловечность» Н. В. Гоголя, унаследованная от А. С. Пушкина. «Всечеловечность» (определение Ф. М. Аостоевского по отношению к таланту А. С. Пушкина) является одной из глубинных интуиций русской души. Подлинный патриотизм предполагает интуитивное стремление к универсализму, к преодолению национальной замкнутости, закрытости, обособленности.

\section{ЗАКАЮЧЕНИЕ}

Возвращаясь к мысли о поиске героем своего «поприща», вспомним стихотворение А. Хармса «Постоянство веселья и грязи», в котором образ Бога имплицитно представлен в образе дворника, который не метет свой мир («место - мести»). 
По словам С. З. Агранович, «подобных безумных текстов в искусстве полно», а «кощунство - почти обязательно для глубоко религиозных русских писателей» (Агранович: Электронный ресурс). По-видимому, исследователь имела в виду соединение несообразных миров, тех, что фиксирует Н. В. Гоголь в своих произведениях, где «нос» исчезает в Благовещенье, а после молитвы вдруг возникает «шишка».

Последняя фраза «Записок сумасшедшего : «А знаете ли, что у алжирского дея под самым носом шишка?» - и снимает, и одновременно подчеркивает трагедийный пафос текста. Эта подчеркнутая оксюмористичность, вероятно, имеет двойное дно. Во-первых, прослеживается установка автора на сотворчество с читателем, о чем свидетельствуют и «интеллектуальные крючки», разбросанные по всему произведению ( «думайте!»). Во-вторых, контрастная смена регистра в сильной текстовой позиции (финале) только акцентирует молитвенное звучание финала.

Художественное произведение не должно быть понятным и понятым до конца и «в этом безумии есть метод». Поиск смысла существования приводит человека к выбору: жить - любить, жить - знать или жить - желать. Очевидно, первый путь - самый сложный, он подразумевает жертвенность (к нему стремится душа Аксентия Поприщина); второй путь актуализирует фраза: «многие знания - многие печали», на третьем пути зиждется антропологическая катастрофа.

\section{ПРИМЕЧАНИЯ}

1 Первое название произведения - «Клочки из записок сумасшедшего».

2 Аксентий (Авксентий) - «возрастающий» (греч.).

\section{СПИСОК АИТЕРАТУРЫ}

Агранович Софья Залматовна [Электронный ресурс] // Анна Шведовская. О психологии и не только. URL: http://shvedovskaya.com/video/lectures/agranovich/ (дата обращения: 29.06.2017).

Балаян, В. (2004) Беседы с мудрецами. Александр Пятигорский. Чистый воздух твоей свободы. Аокументальный фильм [Электронный ресурс] // Телеканал «Россия-Культура»: http:// tvkultura.ru/video/show/brand_id/29551/episode_id/959968/video_id/966041 (дата обращения: 06.06.2017).

Бахтин, М. М. (1979) Проблемы поэтики Аостоевского. М. : Советская Россия. 320 с.

Белинский, В. Г. (1952) О русской повести и повестях г. Гоголя // Н. В. Гоголь в воспоминаниях современников / ред., предисл. и коммент. С. И. Машинского. М. : Художественная дитература. 736 с. С. $340-348$.

Блок, А. (1982) Аитя Гоголя // Блок, А. Собрание сочинений : в 6 т. А. : Художественная литература. T. 5.406 c.

Гоголь, Н. В. (1984) Записки сумасшедшего // Гоголь, Н. В. Собрание сочинений : в 8 т. М. : Правда. Т. 3.336 с. С. $164-184$.

Золотусский, И. П. (1979) Гоголь. М. : Молодая гвардия. 512 с.

Колесов, В.В.(2015) «Жизнь происходит от слова...». СПб. : Златоуст. 516 с.

Мамардашвили, М. К. (1992) Как я понимаю философию. 2-е изд., изм. и доп. / сост. и общ. ред. Ю. П. Сенокосова. М. : Прогресс : Культура. 414 с.

Померанц, Г. С. Перевес интеллекта над интуицией делает жизнь скучной историей [Электронный ресурс] // Григорий Померанц, Зинаида Миркина. URL: http://www.pomeranz.ru/p/ 2006_14_1.htm (дата обращения: 13.07.2017).

Потебня, А. А. (1999) Полное собрание трудов: Мысль и язык / подг. текста Ю. С. Рассказова, О. А. Сычева. М. : Аабиринт. 300 с. 
Пятигорский, А. (2016) Мышление и наблюдение: четыре лекции по обсервационной философии. СПб. : Азбука-Аттикус. 188 с.

Мартин Хайдеггер - Эрнст Кассирер. Семинар (2001) // Фауст и Заратустра. СПб. : Азбука. 320 с. С. $130-141$.

Фромм, Э. (1995) Здоровое общество // Психоанализ и культура. М. : Юристъ. 623 с. С. $273-596$.

Хайдеггер, М. (2011) Бытие и время / пер. с нем. В. В. Бибихина. М. : Академический проект. 460 c.

Шарипов, А. Мераб Мамардашвили: Когда человек перестает быть человеком? [Электронный ресурс]// Econet: включи сознание. URL: https://econet.ru/articles/153833-merab-mamardashvili-kogda-chelovek-perestaet-byt-chelovekom (дата обращения: 29.06.2017).

Аата поступления: 23.07.2017 2.

\author{
THE APPREHENSION OF AN ANTHROPOLOGICAL CATASTROPHE \\ IN "DIARY OF A MADMAN" BY N. V. GOGOL \\ V. N. MATONIN, N. N. BEDINA, E. N. EGOROVA \\ NORTHERN (ARCTIC) FEDERAL UNIVERSITY NAMED AFTER M. V. LOMONOSOV
}

"Diary of a Madman" (1834), a short story by the Russian writer N. V. Gogol, is one of the bestknown philosophical writings of the author. N. V. Gogol's work is being considered in the context of the dialogue conception of culture by M. M. Bakhtin, which implies the possibility of the text "surpassing" its author, as well as the possibility of the author's ingenious epiphanies.

The image of the main character Aksenty Ivanovich Poprishchin reflects the premonition of an "anthropological catastrophe" (M. Mamardashvili). Its features were embodied by Gogol with a surprising accuracy in the artistic image much earlier than it was comprehended in philosophcal categories. The more absorbed the reader becomes in the hero's consciousness, the more evident for them becomes the ontological loneliness of the man, which is embodied in the madness of the hero "thrown into the world" (M. Heidegger). In search of a way out of human bounds and human finiteness, Gogol follows the track designatd by E. Cassirer, opposing M. Heidegger, into the meaningful existence of cultural forms. Apprehending the danger of an anthropological catastrophe, Gogol, through his hero, invites the man to find grounds for their existence in sacrificial service and prayer (faith). In the world of illusions (in «madness of unthinking»), sacrifice and suffering are a way to return to reality, impossible without the sense of Motherland. In this sense, the issue of the national character of Gogol's prose appears topical.

In the language and set of images of the story, the author finds a way to show the universal in the national, since genuine patriotism presupposes an intuitive aspiration for universalism, to overcome national isolation and narrow-mindedness.

Keywords: N. V. Gogol; Russian literature; "Diary of a Madman”; anthropological catastrophe; ontological loneliness; meaningful existence

\title{
REFERENCES
}

Agranovich Sof'ia Zalmatovna. Anna Sbvedovskaia. O psikbologii i ne tol'ko [online] Available at: http://shvedovskaya.com/video/lectures/agranovich/ (access date: 29.06.2017). (In Russ.).

Balaian, V. (2004) Besedy s mudretsami. Aleksandr Piatigorskii. Chistyi vozdukh tvoei svobody. Dokumental'nyi fil'm. Telekanal "Rossiia-Kul'tura» [online] Available at: http://tvkultura.ru/ video/show/brand_id/29551/episode_id/959968/video_id/966041 (access date: 06.06.2017). (In Russ.).

Bakhtin, M. M. (1979) Problemy poetiki Dostoevskogo. Moscow, Sovetskaia Rossiia. 320 p. (In Russ.).

Belinskii, V. G. (1952) O russkoi povesti i povestiakh g. Gogolia. In: N. V. Gogol'v vospominaniiakb sovremennikov / ed. by S. I. Mashinskii. Moscow, Khudozhestvennaia literatura. 736 p. Pp. 340-348. (In Russ.). 
Blok, A. (1982) Ditia Gogolia. In: Blok, A. Sobranie socbinenii : in 6 vol. Leninhrad, Khudozhestvennaia literatura. Vol. 5. 406 p. (In Russ.).

Gogol', N. V. (1984) Zapiski sumasshedshego. In: Gogol', N. V. Sobranie socbinenii : in 8 vol. Moscow, Pravda. Vol. 3. 336 p. Pp. 164-184. (In Russ.).

Zolotusskii, I. P. (1979) Gogol'. Moscow, Molodaia gvardiia. 512 p. (In Russ.).

Kolesov, V. V. (2015) «Zhizn’ proiskbodit ot slova...». St. Petersburg, Zlatoust. 516 p. (In Russ.).

Mamardashvili, M. K. (1992) Kak ia ponimaiu filosofiiu. $2^{\text {nd }}$ ed. / ed. by Iu. P. Senokosov. Moscow, Progress, Kul'tura. 414 p. (In Russ.).

Pomerants, G. S. Pereves intellekta nad intuitsiei delaet zhizn' skuchnoi istoriei. Grigorii Pomerants, Zinaida Mirkina [online] Available at: http://www.pomeranz.ru/p/2006_14_1.htm (access date: 13.07.2017). (In Russ.).

Potebnia, A. A. (1999) Polnoe sobranie trudov: Mysl' $i$ iazyk / preparation of the text by Iu. S. Rasskazov and O. A. Sychev. Moscow, Labirint. 300 p. (In Russ.).

Piatigorskii, A. (2016) Mysblenie $i$ nabliudenie: chetyre lektsii po observatsionnoi filosofii. St. Petersburg, Azbuka-Attikus. 188 p. (In Russ.).

Martin Khaidegger - Ernst Kassirer. Seminar (2001). In: Faust i Zaratustra. St. Petersburg, Azbuka. 320 p. Pp. 130-141. (In Russ.).

Fromm, E. (1995) Zdorovoe obshchestvo. In: Psikboanaliz i kul'tura. Moscow, Iurist». 623 p. Pp. 273-596. (In Russ.).

Khaidegger, M. (2011) Bytie i vremia / transl. from Germ. by V. V. Bibikhin. Moscow, Akademicheskii proekt. 460 p. (In Russ.).

Sharipov, A. Merab Mamardashvili: Kogda chelovek perestaet byt' chelovekom? Econet: vkliuchi soznanie [online] Available at: https://econet.ru/articles/153833-merab-mamardashvili-kogda-chelovek-perestaet-byt-chelovekom (access date: 29.06.2017). (In Russ.).

Submission date: 23.07.2017.

Матонин Василий Николаевич - доктор культурологии, профессор кафедры культурологии и религиоведения Северного (Арктического) федерального университета имени М. В. Аомоносова. Адрес: 163002, Россия, г. Архангельск, наб. Северной Авины, д. 17. Тел.: +7 (8182) 21-61-00. Эл. aspec: matoninv@yandex.ru

Бедина Наталья Николаевна - кандидат филологических наук, доцент кафедры культурологии и религиоведения Северного (Арктического) федерального университета имени М. В. Аомоносова. Алрес: 163002, Россия, г. Архангельск, наб. Северной Авины, д. 17. Тел.: +7 (8182) 21-61-00. Эл. aspec: bedina-nat@yandex.ru

Егорова Екатерина Николаевна - кандидат филологических наук, доцент кафедры культурологии и религиоведения Северного (Арктического) федерального университета имени М. В. Аомоносова. Адрес: 163002, Россия, г. Архангельск, наб. Северной Авины, д. 17. Тел.: +7 (8182) 21-61-00. Эл. aApec: ruslit1611@yandex.ru

Matonin Vasiliy Nikolayevish, Doctor of Culturology, Professor, Department of Culturology and Religion Studies, Northern (Arctic) Federal University named after M. V. Lomonosov. Postal address: 17, Severnoy Dviny Emb., Arkhangelsk, Russian Federation, 163002. Tel.: 7 (8182) 21-61-00. E-mail: matoninv@yandex.ru

Bedina Natalya Nikolayevna, Candidate of Philology, Associate Professor, Department of Culturology and Religion Studies, Northern (Arctic) Federal University named after M. V. Lomonosov. Postal address: 17, Severnoy Dviny Emb., Arkhangelsk, Russian Federation, 163002. Tel.: 7 (8182) 21-61-00. E-mail: bedina-nat@yandex.ru

Egorova Ekaterina Nikolayevna, Candidate of Philology, Associate Professor, Department of Culturology and Religion Studies, Northern (Arctic) Federal University named after M. V. Lomonosov. Postal address: 17, Severnoy Dviny Emb., Arkhangelsk, Russian Federation, 163002. Tel.: 7 (8182) 21-61-00. E-mail: ruslit1611@yandex.ru 